\title{
La pandemia por SARS-CoV-2 (COVID-19) y el replanteamiento de las estrategias en la actividad de donación y trasplantes
}

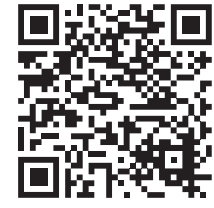

\author{
The SARS-CoV-2 (COVID-19) pandemic and the rethinking of \\ strategies in the donation and transplantation activity
}

\author{
José Salvador Aburto-Morales* \\ * Director General del Centro Nacional de Trasplantes.
}

El trasplante de órganos, tejidos y células se ha convertido en una práctica mundial que puede prolongar la vida y mejorar su calidad. Sin embargo, las capacidades para realizar trasplantes en los diferentes países son heterogéneas.

En México, a 10 años de realizado el primer trasplante, se inició la regulación de éstos en el título décimo del Código Sanitario de los Estados Unidos Mexicanos y 27 años más tarde, el 26 de mayo de 2000, se decretó la creación del Centro Nacional de Trasplantes (CENATRA). En 2003, CENATRA se transformó en un órgano desconcentrado normativo responsable de la coordinación del Subsistema Nacional de Donación y Trasplantes, mientras que las atribuciones de vigilancia y control sanitario fueron transferidas a la Comisión Federal para la Protección contra Riesgos Sanitarios (COFEPRIS).

De 1963 a diciembre de 2019, de acuerdo con datos del Registro Nacional de Trasplantes, se ha logrado realizar más de 120 mil trasplantes de órganos y tejidos. En 2019, la tasa de donación por muerte encefálica fue 4.5 por millón de habitantes (pmh) y la tasa de trasplantes de órganos fue de $25.6 \mathrm{pmh}$, cifra por debajo de los 116 trasplantes realizados pmh en España, país número uno en el mundo. ${ }^{2}$ Para esa misma fecha, aún persistían en lista de espera 22,602 personas, lo que señala la escasa atención a la demanda creciente de órganos y tejidos, consecuencia, entre otras causas, del aumento de las enfermedades crónico-degenerativas en nuestro país.

Se ha documentado que otros factores relacionados con esta insuficiente atención a la demanda, tienen que ver no sólo con la «cultura de la donación», sino también con dificultades estructurales históricas del propio sistema de salud, como la cobertura universal que pueda garantizar el acceso a los trasplantes sin importar la condición laboral o económica de las personas, elemento clave del éxito del llamado «Modelo español».3 En nuestro país, mientras que en las instituciones de seguridad social los pacientes pueden acceder a la inmunosupresión postrasplante, en las instituciones para población sin este tipo de aseguramiento, no se garantiza ese acceso. Las fuentes de financiamiento son diversas y no específicas para la actividad de donación y trasplantes. Algunos otros factores clave de modelos internacionales exitosos son la existencia de una organización y un sistema que involucra a todas las partes interesadas, desde profesionales de la salud, instituciones de salud, organizaciones de la sociedad civil, prestadores de servicios aéreos, pero, principalmente, al gobierno, que prioriza esta actividad como una política de Estado, con el financiamiento necesario para la atención de los requerimientos de la Organización Nacional de Trasplantes (ONT) y del sistema que incluye la capacitación y remuneración de los profesionales de la salud involucrados, con los resultados ya mencionados. 
Hoy, a 20 años de la operación del CENATRA, la pandemia por SARS-CoV-2 (COVID-19) ha venido a mostrar la necesidad de replantear las estrategias con las que se ha estado operando. Los hospitales han sido reconvertidos para la atención de esta emergencia sanitaria y los recursos humanos, financieros y materiales han sido reorientados para contenerla. La actividad se ha reducido a menos de 10 trasplantes de donador fallecido por mes. Si se quiere reimpulsar la actividad de donación y trasplante para alcanzar los estándares internacionales y la suficiencia en la atención de las necesidades, así como garantizar la seguridad de los pacientes y de los profesionales de la salud involucrados; además de adaptar los procesos debido a la presencia del virus, será necesario repensar el «Modelo mexicano» vigente.

Si bien en 2018 se amplió el catálogo de intervenciones del Seguro Popular para incrementar la cobertura de los trasplantes, no fue incluido el trasplante renal para mayores de 18 años o el trasplante de córnea en menores de esta edad. ${ }^{4}$ Con la creación del Instituto Nacional de Salud para el Bienestar (INSABI) y el profundo interés presencial de garantizar el cumplimiento del artículo $4^{\circ}$ constitucional, se vislumbra una oportunidad para impulsar el acceso universal y gratuito a los trasplantes de órganos y tejidos para los mexicanos que así lo necesiten, que permita disminuir la mortalidad, mejorar la calidad de vida de las personas, optimizar la operación de los establecimientos de salud, generar retornos positivos a la economía del país y, con ello, generar confianza en la población sobre las acciones que sociedad y gobierno emprenden en favor de los mexicanos.

Nada de esto sería posible sin la participación activa de la sociedad civil organizada, organizaciones científicas como la Sociedad Mexicana de Trasplantes, los gobiernos de las entidades federativas y la participación de los organismos internacionales y de los sectores público y privado, que permitan estructurar redes integrales, integradas y regionalizadas de coordinadores hospitalarios, equipos quirúrgicos, recursos físicos, humanos y materiales. Lo que favorecerá, por una parte, optimizar recursos a través de la adaptación de la infraestructura vigente como centros hospitalarios especializados en trasplantes, y realizar una asignación de órganos y tejidos más equitativa a través de la disponibilidad de laboratorios de histocompatibilidad.

Datos de la Unidad de Análisis Económico de la Secretaría de Salud señalan que el ingreso prome- dio recuperado por reinserción a la vida productiva de las 21,279 personas en lista de espera en 2018, en el periodo de vida del injerto (10 años), sería de $\$ 37,733$ millones de pesos para el sistema de salud, lo que equivale a un retorno de 2.6 pesos por cada peso invertido. ${ }^{5}$ El promover la donación de personas fallecidas, que actualmente representa $30 \%$ de los trasplantes renales, generaría ahorros de 171 mil pesos por trasplante y de 215 millones al Sistema de Salud, considerando el periodo de vida del injerto, al lograr incrementar a $70 \%$ la donación de personas fallecidas.

La atención al tema de donación y trasplantes es un asunto que compete a todos los mexicanos. Sus retos son, en parte, reflejo del estado del sistema de salud. Avanzar hacia una política de Estado que atienda la problemática histórica del Subsistema Nacional de Donación y Transplante (SNDyT), agudizada por la presencia del virus SARS-CoV-2, implica acciones intersectoriales e interinstitucionales para fortalecimiento de la actividad de donación y trasplante a través de su financiamiento. Al ser la equidad, la maximización de eficiencia y la lucha contra la corrupción los pilares del Gobierno Federal, se busca lograr el fortalecimiento de este Subsistema Nacional y contribuir a garantizar el cumplimiento de nuestro artículo $4^{\circ}$ constitucional, para transformarlo en un sistema efectivo y transparente, con amplio impacto social.

\section{REFERENCIAS}

1. Aburto JS, Romero J, Gabilondo F. Donación y trasplantes de órganos y tejidos en México cinco décadas de evolución y perspectivas. La Medicina es Así. [Acceso 9 de agosto de 2020] Disponible en: https://www.asieslamedicina.org.mx/donacion-ytrasplantes-de-organos-y-tejidos-en-mexico-cinco-decadas-deevolucion-y-perspectivas/

2. Organización Nacional de Trasplantes. Actividad de donación y trasplante. España: 2019.

3. Matesanz R. El modelo español. España: Aula Médica; 2008.

4. Comisión Nacional de Protección Social en Salud. Catálogo Universal de Servicios de Salud. Ciudad de México: 2018. Disponible en: http://www.documentos.seguro-popular.gob.mx/ dgss/CAUSES_2018c.pdf.

5. Gutiérrez DC, Camacho ChA, Canseco RN. Perspectiva económica del trasplante renal para el sector público. Boletín Estadístico Inf BEI-CENATRA. 2018[Accessed August 9, 2020]; 3 (2). Disponible en: https://www.gob.mx/cms/uploads/ attachment/file/484466/BEI-CENATRA_Vol._III_No._2_ENEDIC_2018_WEB.pdf.

Correspondencia:

Dr. José Salvador Aburto-Morales

E-mail: jose.aburto@salud.gob.mx 